\title{
Voci Di TRANS-POESIA DALLE Americhe a Carmelo Bene
}

Nicola Licciardello

ABSTRACT L'esilio alla conquista della Terra Promessa genera meticciati, trans-culturazioni, sincretismi, che rinnovano le lingue delle comunità umane. I poeti ne sono i promotori, perché la poesia è già iper-traduzione, trans-creazione di processi intimi e storici, legata all'oralità e al ritmo. Nelle Americhe, del Nord come del Sud, la musica e la poesia danno forma a trans-culturazioni globali, spesso riprese nel resto del mondo. Quella americana è una trans-poesia che canta il riscatto dell'uomo, la libertà e l'amore della natura. Come ogni vera poesia e ogni processo storico, può essere un atto salvifico, esoterico: comunicazione ritmica che attraversa barriere linguistiche e identità, e così una delle poche vie che hanno gli uomini per riconoscersi fratelli e figli. Il saggio illustra questa tesi esaminando la poesia di Lezama Lima, Joyce, Paz, de Campos, dei Beats e di Carmelo Bene.

PAROLE CHIAVE Trans-culturazione; sincretismo; trans-poesia; J. Lezama Lima e "Orígenes" (Cuba); Beats (Usa); Carmelo Bene. 
RESLMO Oexíliopara a conquista da Terra Prometidageramestiços, trans-culturações, sincretismos, que renovam as linguas das comunidades humanas. Os poetas são seus promotores, porque a poesia é já hiper-tradução, trans-criação de processos íntimos e históricos, ligadaàoralidade e ao ritmo. Nas Américas, tanto do Norte como do Sul, a música e a poesia dão forma a trans-culturações globais, freqüentemente retomadas no restante do mundo. A americana é uma trans-poesia que canta o resgate do homem, a liberdade e o amor pela natureza. Como toda verdadeira poesia e todo processo histórico, pode ser um ato salvífico, exotérico: comunicação rítmica que atravessa barreiras lingüísticas e identidades, e ser, assim, um dos poucos caminhos de que os homens dispõem para reconhecer-se irmãos efilhos. O ensaio ilustra essa tese examinando a poesia de Lezama Lima, Joyce, Paz, de Campos, dos Beats e de Carmelo Bene.

PALAVRAS-CHAVE Trans-culturação; sincretismo; trans-poesia; J. Lezama Limae "Orígenes" (Cuba); Beats (Eua); Carmelo Bene.

IBSTRACT Exile to conquer the Promised Landbrings forth blackmoors, transculturation, syncretism, that renew the languages of human communities. Poets are their champions, because poetry is already hyper translation, transcreation of internal and historic processes, linked to orality and rhythm. In North and South Americas, music and poetry lend shape to global transculturation, frequently resumed across the world. American poetry is transpoetry that sings about the rescue of man, freedom and love of nature. Like all pure poetry and every historic process, it can be a salvaging, esoteric act: rhythmic communication that surpasses language and identity barriers and therefore becomes one of the few paths available for men to recognize one another as brothers and sons. The essay illustrates this thesis by looking into the poetry of Lezama Lima, Joyce, Paz, Campos, Beats and Carmelo Bene.

KEXWORDS Transculturation; syncretism; transpoetry; J. Lezama Lima and "Origenes" (Cuba); Beats (US); Carmelo Bene. 


\title{
1.Trans-culturazione, sincretismo, transpoesia ${ }^{1}$
}

\author{
Vieni, renderò il continente indissolubile, creerò la più \\ splendida razza su cui il sole abbia mai brillato, creerò divine terre \\ magnetiche, con l'amore dei compagni, con il diuturno amore dei compagni. \\ Pianterò la fratellanza, folta come gli alberi lungo \\ tutti i fiumi d'America, e lungo le sponde dei grandi laghi, e su tutte \\ le praterie, renderò inseparabili le città con le braccia l'una al collo \\ dell'altra, con l'amore dei compagni, con il virile amore dei
} compagni. Per te questi da parte mia, democrazia, per servirti, mia donna! Per te, per te faccio vibrare questi canti. ${ }^{2}$ Walt Whitman

L'avvenire andrà verso la compenetrazione di tutti i valori musicali dei popoli; a una progressiva panmixia delle arti, come dei pigmenti cosi delle culture. A una sinfonia dal significato universale, come auspicava il genio di Beethoven - che qualcuno, per l'oscurità sulla sua ascendenza, ha sostenuto avesse qualcosa di mulatto. ${ }^{3}$ José Vasconcelos via Thoreau ed Emerson), risponde un secolo dopo il proclama panlatinamericano di Vasconcelos. Come il bolivarismo di un José Martí, al monroismo, all'assimilazionismo angloprotestante del Nordamerica contrappone una "fratellanza" cattolica dei latinos nel Centro-Sudamerica All'umiltà delle origini quacchere e all'umanitarismo "scientifico" di Whitman (carisma insuperabile per la missione imperiale degli Stati Uniti), Vasconcelos oppone la "facilità di simpatia con gli estranei che hanno i latini" (al contrario degli anglosassoni, che non si mescolano con i popoli conquistati) - verificabile nei buoni rapporti fra missionari e indios in Brasile, e attualissima nei programmi degli indios neopresidenti in Sudamerica.

Avvento o riscatto: quando il mito della Terra Promessa incontra la realtà del Nuovo Mondo, la Gerusalemme Celeste trova il suo posto lì, dove sorgerà la vera Umanità, oppure una Democrazia "finale" che rifonde la storia di tutti i popoli e ogni individuo abbraccia. Non l'eguaglianza accomuna pellegrini, coloni e schiavi, ma lo spezzarsi dell'identità, l'esilio dalla vecchia Eurasia e Africa,

1. Ė qui rielaborata la comunicazione Poética e Tradução: dos cubanos, Guillén, Lezama Lima e o Grupo da Revista "Orígenes" até os norteamericanos Allen Ginsberg e Gary Snyder - da me tenuta presso la Facoltà di Lettere dell'Università Federale di Vitória (Espirito Santo), il 26 luglio 2004, per invito della Prof. Ana Beatriz Gonçalves e del Prof. Paolo Spedicato - i quali vivamente ringrazio. Occorre qui immaginare le voci dei poeti fatte ascoltare in quell'occasione.

2. Walt Whitman, Foglie d'erba, trad. Giuseppe Conte, Oscar Poesia Mondadori 1991.

3. José Vasconcelos (1882-1959), La raza cósmica, Misión de la raza iberoamericana, Obras Completas t. II, Libreros Mexicanos, México 1958 (la parola "razza" è qui usata nel senso esoterico, steineriano, di "razza cosmica"). 
una morte - il prezzo, il sacrificio necessario ${ }^{4}$ alla libertà di trans-culturazione. Trans: trapianto e trasfusione nel corpo estraneo sono innanzitutto un passaggio di cose, una traduzione fisica di uomini e lingue, traslazione di visioni del mondo su un nuovo territorio - in attrito, conflitto, rapporto con i nativi e la loro etnopoetica. Fra dominati e dominanti una dolorosa (o stimolante) creolizzazione - non un "multiculturally correct dialogo inter-culturale", ma la trans-formazione di un nuovo ordine, di (dis)equilibri fra i caratteri di partenza riconoscibili nella sintesi (religione, arti, folklore, teatro, poesia). A volte un'osmosi, un processo storico di sincretismo - a suo tempo il Graecia capta romanum victorem coepit, l'ellenismo, il cristianesimo paolino ${ }^{5}$, etc.

“Transculturazione" definisce l'etnomusicologo cubano Fernando Ortiz ${ }^{6}$ il doppio processo di de-culturazione (espianto dall'Africa e dall'Europa) e neo-culturazione (nell'isola caraibica, colonia ispanica) che costituirà l'identità "ritmica" di Cuba - quella cubanía senza distinzioni di classe che inizia dalla popolare santeria, "difensivo" sincretismo "pagano"-cattolico (analogo al candomblé brasiliano $\mathrm{e}$ al voodoo haitiano). L"'afrocubano" e la sua oralità venivano così promossi a fattori vitali di una cultura transnazionale e "transrazziale". In effetti, fu il poeta nero nordamericano Langston Hughes a incoraggiare il mulatto cubano Nicolás Guillén, amico di Ortiz come lo furono gli andalusi Federico Garcia Lorca, Juan Ramón Jiménez e María Zambrano in visita all'Avana, e i cubani Alejo Carpentier (scrittore), Rita Montaner (cantante), Wilfredo Lam (pittore).

Se la vita culturale delle comunità meglio dell'antropologo ${ }^{7}$ parla per esse, è perché nelle ricreazioni popolari, nei processi di trans-culturazione o sincretismo avviene qualcosa di sotterraneo ("occulto" politicamente) e misterioso, non-lineare, persino trascendente - cioè salutare e salvifico - l'esoterico o iniziatico stesso che opera nel poeta. Più che mai, nelle presenti tenebre del terrore globale, serve trovare una chiave esoterica, unificante nell'ascolto del "canto" poetico, decifrando il processo dell'Opus, che separa ciò che vive (luce) da ciò che cade (tenebre), risalire la scala dei "quattro sensi della scrittura"8. Può farlo solo chi abbia a cuore un riscatto planetario,

4. Sul dover uscire, almeno una volta, dalla propria tradizione (non dalla Tradizione), sul dover errare da "infedeli", prima di poter ri-abitare l'origine, torna di recente anche Abdelwahab Meddeb ( $L$ a malattia dell'Islam) con il suo studio del poeta zen Saigyo dimostrando l'attualità di una goethiana Weltliteratur.

5. Le differenti forme di cristianesimo nel tempo e nei luoghi hanno improntato varie culture: basti pensare alla odierna "transculturazione protestante" nella cattolico-pagana Italia (un caso di globalizzazione) - da cui la sua crisi d'identità.

6. In Contrapunteo cubano del tabaco y el azúcar (L'Avana 1940) - dove tratta Señor Tobacco y Doña Azucar come Marx faceva con "Madame la Terre e Monsieur le Capital".

7. Dopo Boas, Malinowski, Levi-Strauss e Tyler - Geertz dichiara: "in fin dei conti, ciò che fa l'antropologo è raccontare" - l'antropologia diventa "narrativa". Consapevole di modificare già con la sua presenza l'ambiente e il soggetto studiato (per un caso nel nord-est del Brasile: Roberto Malighetti, Il Quilombo di Frechal, Milano 2004), e del suo tradurre ciò che a sua volta "traduce" l'ambigua voce del native informant - emblematica l'enorme ripercussione politica della "traduzione" nel caso di Malinchin, interprete di Cortéz e traditrice di Montezuma; si veda: Emily Apter, Translation in a Global Market (2001). In effetti, dopo l'irruzione dell'Altro, del sacro nell'Europa di Artaud, Callois e Bataille, il pensiero postmoderno tenta un "riciclaggio" del primitivo con il dialogo etnopsichiatrico (Ernesto De Martino, Piero Coppo) o con lo "sciamanesimo trans-culturale" (Micheal Harner) e la sua etnobotanica "estatica" (Carlos Castaneda, Carl Ruck) - in ogni caso con una Psicologia Trans-Personale (Stanislav Grof, Ken Wilber). E cosi l'apertura epistemologica de Il dono (1926) di Marcel Mauss rifiorisce nei postmoderni Lo spirito del dono di Jacques Godbout, o Morte e rinascita del dono di Charles Champetier, o nell'“economia del dono" di Serge Latouche. Edward Said (Orientalism, 1978; trad. ital. 1999; Cultura e imperialismo, 1988) contrapponeva all'imperialismo culturale dell'Occidente la metamorfosi dei migranti, il contrappunto musicale nelle ri-narrazioni del mondo, tuttora mancanti; con la fine della Ragione eurocentrica, tentano una globalizzazione "multiculturale" i Post-colonial (o Subaltern) Studies e le teorie comparative: Dipesh Chakrabarthy, nel provocatorio Provincializzare l'Europa (2005); Iain Chambers in Donne e multiculturalismo (2005); George Steiner in Dopo Babele - suggeriscono una "ibridazione originaria" delle culture umane; ma Gayatri Spivak, in Critica della ragione post-coloniale (2005), sostiene un radicale "reimmaginare il pianeta, l'alterità di un soggetto planetario, fonte e destinatario di imperativi etici dell'im-possibile".

8. Non lo fanno nemmeno l'sinvariante creatività del linguaggio" di Chomsky, l"essotopica, critica compartecipazione" di Todorov, la "semiosfera" di Lotman, la "polifonia dell'enunciato linguistico" di Bachtin. Un'eccellente discussione su comparatistica e traduttologia ha comunque svolto in Italia la rivista di poesia comparata "Semicerchio" di Firenze, diretta da Francesco Stella - coordinatore della collana Poesia Straniera di "Repubblica". 
trans-nazionale (Gayatri Spivak), trans-disciplinare (Homi Bhabha), trans-religioso ${ }^{9}$ (Coomaraswamy, Panikkar), olistico (Bateson). Per "riunire ciò ch'è sparso", bisogna ripescare l'anima dei fatti, l'intenzione comunicativa, l'analoga bi-polarità di un'immagine psichica o di un simbolo-archetipo in tradizioni e nazioni diverse (Jung, Hillman, Durand, Campbell) ${ }^{10}$, "essere in risonanza con l'universo" (Eliade, Zolla, Schneider), respirare la fiamma d'amor viva (Dante), che riscatta dagl'inferi la Parola perduta (Zambrano), evocare l'“arca vivente dei simboli" (Guenon) come un'Aurora, allegoria di rinascente fratellanza - possibile solo ri-conoscendosi figli di una (tr)ascendenza comune - rivedendo ciò che nel sogno e nel "mondo immaginale" (Bæhme, Corbin, Bachelard) era il comune Albero della vita, rimasto celato nella varietà babelica dei suoi nomi.

La diversità delle lingue (von Humboldt, 1837) è un "patrimonio dell'umanità" che Claude Hagège invoca di proteggere ${ }^{11}$ - ma il "servizio" del traduttore consiste nel "redimere, liberare nella traduzione la pura lingua che è racchiusa in un'altra" (Benjamin), mirando a quell'adamitica lingua "naturale" dell'umanità - "non accessibile alle singole, ma solo alla totalità delle loro intenzioni reciprocamente complementari". La lingua in cui le cose erano chiamate secondo la loro "essenza". cioè il loro "ritmo", o il loro "geroglifico" (Novalis). Per l'autore come per il traduttore allora, la "grandezza" di un poeta si verifica nella sua traducibilità: possibile quanto più il suo ritmo ri-genera il ritmo (e dunque l'immaginario) di una comunità di parlanti-ascoltanti - evento che le apparenta tutte nel mondo.

La poesia è una tecnica di "traduzione" dell'ineffabile, un logos dell'indicibile - il poeta "traduce" dalla e nella "lingua franca" di qualcuno o qualcos'oltre l'immediato se stesso (per Rimbaud "l'Io è un Altro"). L'enunciato poetico, nelle sue radici trans-intime, è di per sé un atto multi-e iper-metaforico, un differenziale, teatrale sintetizzatore di usi della lingua (nativo, quotidiano, straniero, non-verbale). Ed essendo la cultura in terra americana già una "speculazione" di quelle europee - il "barocco americano" un iperbarocco - la sua poesia accoglie consapevolmente il canto di mondi lontani (degli antenati, di arrivo, di altri popoli), configurando cosi una trans-poesia. Se Whitman è l'Omero aurorale del "Novus Ordo", il Virgilio dell'impero per la poesia del Novecento è Ezra Pound - che "trapianta" lingue classiche e orientali in una transpoesia aspra, "tosca" - prediligendo il significato, e la singola parola, al flusso del significante - rinviando però a un "trans" di oralità americana.

Di una trans-oralità da gran pellegrino europeo, invece, testimonia la composizione del Finnegans Wake (sul cui plurilinguismo si è tentata più di una lettura alchemica): Joyce volle fare il traduttore di se stesso in francese e in italiano, e a Trieste (il cui dialetto parlava e scriveva benissimo) con Nino Frank provava le sue versioni italofone ad alta voce, anzi "cantandosele"12. Questo gli rivelava a suo modo lo spirito o genio delle lingue ("l'inglese ha un ritmo jazz, l'italiano un andamento operistico"13), consentendogli di "giocarle" deformando il fonosim-

9. Non il "dialogo inter-religioso" (dove ognuno rimane attaccato alla sua religione) - che ha tuttavia un ruolo "sociale" quando non è laico "relativismo" culturale: il nihilismo è stata la coscienza critica della modernità, ma il postmoderno decostruzionismo (Derrida, Deleuze, Nancy) rimane "troppo umano", soggettivista e immanentista - appiattendo la verticalità che esisteva anche nell'antico stoicismo e persino nell'epicureismo. Il sincretismo infatti non va confuso con l'eclettismo, personale scegliere da varie culture ciò che piace per farne un bel mosaico.

10. Per corrispondenze iconologiche: Samuel Marti, Mudra. Manos simbólicas en Asia y America, Mexico 1971; José Argüelles, The Mayan Factor: Path beyond Technology, Santa Fe, New Mexico 1987.

11. Alla Fiera del Libro di Torino 2005 e in Morte e rinascita delle lingue (Milano 2002).

12. James Joyce, Finnegans Wake (libro I, V-VIII), trad. e cura di Luigi Schenoni. Oscar Mondadori 2001; e il preziosissimo Anna Livia Plurabelle di James Joyce, con traduzione in francese di Samuel Beckett e altri, versione italiana di James Joyce e Nino Frank - cura Rosamaria Bollettieri Bosinelli, introduzione di Umberto Eco, Torino 1996.

13. Umberto Eco, Dire (quasi) la stessa cosa, Milano 2003. 
bolismo della parola e il ritmo della frase, per otrenere un irresistibile effetto irrisorio - come in quel Ostrigotta, ora capesco, sostitutivo di un'espressione intraducibile - in un work in progress virtualmente infinito, come il gioco di correzioni di chi scrive al computer. Riscoprendo il "banale" mimetico translinguistico delle culture orali (come Cervantes fa parlare Sancho Panza), dichiarava: "Padre Dante mi perdoni, ma io sono partito da questa tecnica della deformazione per raggiungere un'armonia che vince la nostra intelligenza, come la musica. Vi siete fermato presso un fiume che scorre? Sareste capace di dare valori musicali e note esatte a quel fluire che vi riempie gli orecchi e vi addormenta di felicità?"

Anche per il gigante cosmopolita Octavio Paz, la poesia "è ritmo, metafora originale che contiene tutte le altre, reincarnazione dell'istante; successione è ripetizione, tempo è non tempo. Capire una poesia vuol dire in primo luogo udirne il suono"14. E in quella Città del Messico da cui parte e dove sempre ritorna, questo suono è un trans-linguaggio ispanico e pre-ispanico, mistico e surrealista, tantrico e buddhista, gli universi dove ha nuotato con la stessa infiammata disperanza nella poesia: "La parola poggia su un silenzio anteriore alla lingua, un presentimento di linguaggio. Il silenzio, dopo la parola, riposa su un linguaggio, è silenzio cifrato. Il testo poetico è il transito fra un silenzio e l'altro, fra l'urlo e il tacere" Così può affermare che solo "Il falso poeta parla di se stesso. L'uomo ispirato, colui che davvero parla, scompare dietro la propria voce, non dice nulla di suo; per la sua bocca parla il linguaggio". Anche per lui, il futuro della poesia "sarà orale, una collaborazione fra macchine parlanti e ascoltanti"

Haroldo e Augusto de Campos (Brasile) appartengono alla schiera oggi esigua di artisti-letterati "universali", spesso firmando insieme alcuni saggi e traduzioni dei grandi della letteratura mondiale: Yugen, Zeami, Majakovskij, Rilke, Mallarmé, Valery, Blake, Donne, Keats, Pound, Joyce, Cummings, Dante, i Provenzali ${ }^{15}$. Di Haroldo è finalmente uscita in Italia un'antologia poetica ${ }^{16}$, che include alcune delle cinquanta Galáxias $^{17}$ - corale sbocciare di trans-poesie senza punteggiatura - e alcune delle sue splendide "trans-creazioni" dantesche in rima incatenata - gioielli fragli altri, che provano l'ariosa penetrazione, l'iridescenza cui egli conduce il pun o mot valise joyciano, e la valenza trans-luminosa, esoterica, cui conduce il suo esplicito richiamo a Benjamin:

Tradurre / Tralucere: Dante conduce l'italiano fino al punto in cui, colto come in pieno volo di metamorfosi, il latino vi traspare nel momento stesso della nominazione, non lingua morta, ma lingua viva in lingua viva. [...] Tutto questo il traduttore deve trans-creare, eccedendo i limiti della sua lingua, straniandone il lessico, compensando una perdita qui con un'intrusione inventiva là, l'infra-traduzione forzata con l'iper-traduzione fortunata, fino a confondere e depotenziare quell'ultima hybris (colpa luciferina, trasgressione semiologica?) che consiste nel trasformare l'originale nella traduzione della sua traduzione. Come lo sguardo di Dante graziato nello sguardo divino, tutto allora può trans-luminarsi, in una fulgida e istantanea

14. In: Octavio Paz, Vento cardinale e altre poesie, trad. e cura di Franco Mogni, Oscar Mondadori 1999.

15. Augusto de Campos, Invenção. De Arnaut e Raimbaut a Dante e Cavalcanti, S. Paulo 2003.

16. Haroldo de Campos, L'educazione dei cinque sensi, a cura di Lello Voce, Metauro, Pesaro 2005

17. Haroldo de Campos, Galáxias (1963-1976), S. Paulo 1984. 
chiarezza. La scrittura paradisiaca si lascia sottoscrivere (l'immagine di un miraggio?) da una doppia luce, sia pure per un attimo ${ }^{18}$

Tralasciamo ora altri esempi importanti di trans-poesia americana - come quella del visionario o piuttosto labirintico Luis Borges (più rilevante è la visionarietà profetica del britannico "iconologo" William Blake), o la schiera di poeti nordamericani della seconda metà del Novecento: neo-neoclassici (Charles Wright, C.K. Williams, il traduttore J.D. Mcclatchy); ecosofici (Robert Creeley, Louise Glück); (multi)etnici per nascita (Florence Anthony, Rita Dove - prima afroamericana "poeta laureata", la creek Joy Harjo, il cheyenne Lance Henson, il chicano Gary Soto), o per biografia e cultura (l'italianista Jorie Graham, il musicale Yusef Komunyakaa); nonché il Nobel Derek Walcott, cullato da bimbo con storie anglofone e caraibiche.

Ci soffermeremo invece su alcune voci paradigmatiche, di cui non a caso abbiamo conoscenza diretta: hanno infatti consapevolmente ripreso in pieno il ruolo dell'oralità nel poeta-cantore, non delegando ad alcuno la lettura dei loro testi in pubblico.

\section{José Lezama Lima}

"Lezama era dell'Avana, come Socrate di Atene e S. Tommaso di Aquino": cosi Maria Zambrano misurò l'eccezionalità di questo poeta, radicato in una città dalla "vocazione universale". Colonnello il padre (morto quando lui aveva otto anni), la madre di borghesia creola, zuccheriera e indipendentista (in crisi per il protettorato statunitense su Cuba) - Lezama studia Diritto, ma è culturalmente onnivoro. Nel ' $36 \mathrm{fa}$ amicizia con la Zambrano al suo primo soggiorno avanero, nel '37 con l'altro andaluso Juan Ramón Jiménez, pubblicando il Coloquio con lui sull'“insularità" della poesia. Fonda le riviste "Espuela de Plata" "Nadie Parecia" "Verbum", dove appare il suo primo poemetto Muerte de Narciso, e tesse quella rete fra le arti figurative, la musica, i saggi e la poesia che darà luogo a "Orígenes", cenacolo d'amici e prestigioso trimestrale internazionale. Lavora al ministero dell'educazione, e con le raccolte di poesia (Enemigo rumor, 1941; Aventuras sigilosas, 1945; La fijeza, 1949; Dador, 1959), le conferenze e i saggi su arte e poesia, cubana e universale, il saluto alla Rivoluzione “incarnazione dell'immagine poetica nella storia" (e al Che "nuovo Viracocha andino") - Lezama rilancia la sfida ispanoamericana di José Martí a un livello metafisico. Troppo complesso per il nuovo regime, che ignora il suo romanzo Paradiso (1966), frutto di una solitudine asmatica ed estatica (la sorella Eloisa esule a Miami, la madre mancata nel '64): né il libro celebrativo di Casa de las Americas all'Avana nel '70, né l'invito in Italia nel '72 a ritirare il Premio Maldoror per Paradiso (tradotto da Valerio Riva) gli valgono il sospirato viaggio in Europa. Muore nel 1976, appena pubblicate in Messico le sue "opere complete" 
Dalla "teleologia insulare del cubano universal" (tema del Coloquio del '36 con Juan Jiménez) parte il "sistema poetico" lezamiano. Come per l'etnomusicologo Fernando Ortiz la musica di Cuba avrebbe incorporato la mitologia negra, cosi per Lezama la poesia cubana - diversamente dalla continentale (la messicana di Alfonso Reyes o la nordamericana di Whitman) - avrebbe "incorporato immediatamente"la ritmica negra, al punto da rendersi cantabile (Nicolas Guillén, Gastón Baquero, etc.). Ma ciò che la distingue da un eclettismo "meticcio, o poesia del sangue, impuro per gli gnostici perché mescolanza di acqua e fuoco", è l'insularità di un amore assoluto e universale come quello nato nell'Isle de France: poesia di chi deve scavare dentro di sé radici e forme comuni all'umanità, superando una nostalgia e una distanza infinita - una poesia-canto del fiore nell'acqua, come quella di José Martí, che resiste e attende la resurrezione. Il suo rimane un "viaggio verso l'ignoto" (Melville: "la nostra ascendenza si perde nella paternità universale") pur cercando nel criollo una reconquista dello "splendore ispanico universale"19 ("Cuba, mia patria prenatale" risponde la Zambrano ${ }^{20}$ ). La fedeltà alla famiglia, alla casa, alla Città è il microscopio per ritrovare l'axis mundi, l'Albero, la Grande Madre, natura e grazia, sovreabundancia alle cui Origini, al cui paesaggio, ai cui ritmi risponde la carità, la ricerca di una trascendente sobrenaturaleza poetica tesa fino al sacrificio.

"Poesia della storia come storia della poesia": in una concezione vichiana, transtorica, di uno stato sempre nascente del linguaggio, la scrittura lezamana è ribelle a qualsiasi distinzione di generi (poesia, saggio, romanzo, epistola). Poeta innanzitutto, ma di una poesia spesso selvatica, illeggibile (versi lunghi e contorti, metafore più psichedeliche che surrealiste creano un imprevedibile "ecologico"), Lezama riparte dallo specchio dell'Androgino, da una pre-sessuale "verginità" avanera, con Muerte de Narciso (1937, scritta alcuni anni prima), per scomporne il mito simbolista (ripreso da Valéry) in 17 ottave di straordinaria tensione e maturità linguistica. Il fonosimbolismo e l'allucinato metaforizzare sono al servizio di un'incalzante, rallentatissima visione "tantrica" della morte: l'agonia inaugurale della poesia rifonde in uno Narciso, Cristo, Icaro - Uomo nell'oltre-Natura.

\section{de: Muerte de Narciso}

Rostro absoluto, firmeza mentida del espejo. El espejo se olvida del sonido y de la noche y su puerta al cambiante pontífice entreabre. Máscara y río, grifo de los sueños. Frío muerto y cabellera desterrada del aire que la crea, del aire que le miente son de vida arrastrada a la nube y a la abierta boca negada en sangre que se mueve.

\section{da: Morte di Narciso ${ }^{21}$}

Viso assoluto, falsa fermezza dello specchio. Lo specchio dimentica il suono e la notte e socchiude la porta al mutante pontefice. Maschera e fiume, grifone dei sogni. Gelido morto e chioma esiliata dall'aria che la crea, dall'aria che l'inganna, sono come vita ridotta alla nube e all'aperta bocca negata in sangue che si muove.

\section{(...)}

19. Vasconcelos (op. cit.): "Quanto avviene nel bacino dei Caraibi appartiene a una razza cosmica, cioè a tutte le culture del mondo: questo è l'America - più giovane di quello Mediterraneo è il suo sincretismo, e dunque più carnevalesco, ma più universale" (ivi); appassionatamente l'argentino Julio Cortázar, scopritore di Lezama, rivendica questa come "genuinità americana". E Mario Vargas Llosa arditamente incalza in una formula: "Un esotismo a rovescio: Lezama fa con l'Europa quello che facevano i simbolisti col Giappone" 20. Vissuta per quattordici anni all'Avana, e con la quale Lezama intrattenne un carteggio fino alla morte. 21.Traduzione e commento di chi scrive in: "Semicerchio. Rivista di poesia comparata" (XXIII, Firenze 2001), e di altre poesie lezamiane nel mensile "Poesia" (176, ottobre 2003); inoltre il sito: http://ww.lezama.it 
Narciso, Narciso. Las astas del ciervo asesinado son peces, son llamas, son flautas, son dedos mordisqueados.

Narciso, Narciso. Los cabellos guiandoflorentinos reptan perfiles,

labios sus rutas, llamas tristes las olas mordiendo sus caderas.

Pez del frio verde el aire en el espejo sin estrías, racimo de palomas ocultas en la garganta muerta: hija de la flecha y de los cisnes.

Garza divaga, concha en la ola, nube en el desgaire,

espuma colgada de los ojos, gota marmórea y dulce plinto no ofreciendo

\section{(...)}

Siatraviersa el espejo hierven las aguas que agitan el oído.

Si se sienta en su borde o en su frente el centurión pulsa en su costado.

Si declama penetran en la miraday se fruncen las letras en el sueño.

Ola de aire envuelve secreto albino, piel arponeada,

que coloreado espejo sombra es del recuerdo y minuto del silencio.

Ya trapasa blancura recto sinfin en llamas secas y hojas lloviznadas.

Chorro de abejas increadas muerden la estela, pidenle el costado.

Asíelespejo averiguócallado, asi Narciso en pleamar fugó sin alas.
Narciso, Narciso. Le corna del cervo assassinato sono pesci, sono fiamme, sono flauti, sono dita mordicchiate.

Narciso, Narciso. Fluendo i capelli serpeggiano profili fiorentini,

le labbra la loro via, fiamme tristi le onde mordono i suoi fianchi.

Pesce di verde freddo nello specchio senza pieghe, un groppo di colombe occulte nella gola morta: figlia della freccia e dei cigni.

Erra l'airone, conchiglia nell'onda, nube di trascuratezza,

schiuma appesa agli occhi, goccia marmorea e plinto che non offre dolce.

\section{(...)}

Se attraversa lo specchio fremono le acque che agitano l'ascolto.

Se siede sul bordo o sulla fronte il centurione lo colpisce al costato.

Se declama le lettere penetrano lo sguardo e si corrugano nel sogno.

L'onda d'aria avvolge il segreto albino, la pelle arpionata,

che il colorato specchio è ombra del ricordo e minuto di silenzio.

Già il biancore trafigge il retto infinito in secche fiamme e foglie piovigginose.

Un rivolo d'api increate morde la stella - esigono il costato.

Così in silenzio indagò lo specchio, così Narciso in alta marea sfuggì senz'ali. 
Ciò che appare una cifra poetica prodigiosamente compiuta, alchemicamente consumata - è passibile invece di deliberati straripamenti o contrazioni. Come avviene in Enemigo rumor del '4l (la prima e certo la più articolata, coerente raccolta), sovrano esercizio di stile specie nella seconda parte, i Sonetos infieles - "infedeli", più che al canone metrico, al repertorio ispanico (Garcilaso, Cervantes, Lope de Vega, Gongora, Quevedo) e in particolare mistico (Juan de la Cruz, Sor Juana Inés de la Cruz) che rimettono in scena. Sono versi di un algido e arcaizzante, definitivo esodo dal Novecento, tersi e disperati madrigali dagli incipit miracolosamente classici (Cuando en el cielo despojado asoma, Como el amor si el tiempo lo detiene, Desdicha de la luz la voz sealzaba) - in cui un io "casuale" (non più causale), l'ombra di un io (Ahora que estoy, golpeo, no me siento) sfiora tangente la rotazione di un paesaggio siderale, che rinnova la morte in un sacrificio metafisico e un'invocazione alla Vergine. Fra il fuoco e il nulla, fra la resistenza della pietra e una resurrezione ora impossibile: "peccato senza colpa, eterna pena / che accompagna e sfigura l'amarezza / di quanto cade, e che nessuno nomina"

Lezama tuttavia non distilla affatto una parola "pura" (la parola perfetta o rarefatta dell'ermetismo, cioè dell'arte separata dalla vita) - ma al contrario procede per concrezioni accumulative e barocche concatenazioni, come i "banchi di molluschi". L'allegoria biologica fa rivivere, scrive Ivette Fuentes, un'idea "danzaria" della poesia che agisce sul sipario dell'“impossibile”, come dimostrano le scenografie teatrali di Dador, primo poemetto che dà il titolo all'ultimo volume poetico (più di duecento pagine) dato alle stampe dall'autore. Come nella danza la sinuosità del gesto seduttivo manifesta una "storia", cosi la poesia disegna l'idea nel filo dei suoi versi, è il gioco gestuale della parola - entrambe evocazione dell'incontro fra morti e viventi. Affine all'Art Nouveau nella analogicità della linea, Forma è il balletto con cui Alicia Alonso nel 1943 inaugura la sua scuola nazionale (che diverrà il Ballet Nacional de Cuba), dal testo Poema scritto per l'occasione da Lezama. D'ora in poi quest'evento ispirerà temi coreografici ai poeti ${ }^{22}$ e artisti di “Orígenes" (e tuttora a nuove generazioni).

Danza qui non afrocubana, ma nel segno classicista, spiritualizzazione evolutiva del corpo, rito e sacrificio del respiro, che ne fa il suo "pandominio" ("il ballerino definizione privilegiata della sapienza"), quasi la destinazione per eccellenza della poesia, anch'essa discorso evolutivo. Il poema stesso è "estasi della forma" a ogni verso, cosi come in ogni figura di danza vi è l'impercettibile pausa, posa, fral'inspirazione e l'espirazione. Questo è il "punto rosa", dice Lezama, l'attimo d'equilibrio del "corpo dilatato" (dirà poi Eugenio Barba) dalla "sovrabbondanza" - così come nella poesia vi è l'attimo di silenzio, aperto all'"infinita possibilità" creativa della metafora. Fra la densità e la levità del respiro nato dalla sovreabundancia è il sorriso: il sorriso "arcaico degli immortali" (Buddha, kouroi greci, etruschi, leonardeschi... la "Virgo Potens" o Vergine Maria lezamiana) pronto però a muoversi, per una compassione insita nel godimento della vittoria sulla stessa estaticità - "fino alla delizia, cioè alegre" 


\section{1. "Orígenes"23}

Nella metafora della poesia come danza della compassione, la "rappresentazione del contrario delle cose, quando le figure tornano al loro germe dopo esser state danzate", è anche necessario saper cadere ("oh astri e demenza sempre dolci / piovono sulla fronte del danzante" scrive Virgilio Piñera): nell'immobile istante in alto dev'esserci consapevolezza della necessaria caduta ("cade come ferito / e morto lo raccoglie / la luce [...] breve è la mia vita, fiore strano / breve è la mia vita, unita alla tua forma / che solo invita a un'ora necessaria", scrive Fina Garcia Marruz). E lo sprofondamento, o la discesa, è il riconoscimento del ciclo nella conoscenza d'amore: “[...] Amore è amare / da una radice nera [...] Amore è prepararsi alla croce, e inchiodarsi alla croce, / e morire e resuscitare / Amore è resuscitare!" scrive Dulce María Loynaz, "signora" della poesia cubana (premio Cervantes 1992), che non fece parte del gruppo di "Orígenes", ma di cui è innegabile una comune fonte d'ispirazione.

Lezama ha nel frattempo offerto ai cubani e, riflesso del riflesso agli europei, le sue resistenze transculturali, i muli potenti nell'abisso o il ponte che non si vede - per passare a estranearsi e a ri-conoscersi in ogni matrice culturale, nell'invisibile fraternità da "corpi di gloria" che ritrovano il compito dell'uomo sulla terra - "quando il mondo della fysis e quello della gnosis avranno una sola voce". Il "convertirsi di ognuno di noi in sua madre", come nella bodhicitta del Buddhismo tibetano o nel cinese Segreto del Fiore d'Oro (in cui occorre un "bagno nel vuoto primordiale per pupare in sé l'Embrione di luce" il soffio sottile del Tao), ritorna infine, fra gli essiccati ritratti delle ultime poesie (Fragmentos a su imán) a "ridursi a un punto nel vuoto" (zen) del niño sabio ch'era promesso, del saggio puer-senex (El pabellon del vacío: “L'aridità nel vuoto / è la prima e l'ultima via? / M’addormento, nel tokonoma / evaporo l'altro che seguita il cammino").

Mai uscito da Cuba, se non per una gita in Messico e un'altra in Giamaica, ma spintosi con l'immaginazione creativa fino al più lontano tao, nel suo rovesciato Paradiso Lezama avrebbe potuto "transcreare" in ispanica alchimia il sufismo o un dantesco Ibn'Arabi ${ }^{24}$, o fertilmente dialogare sul sacro al Collége de Sociologie della Parigi anni '30 con Mauss e poi Bataille, con la Scuola di Francoforte sull'inscindibilità di illuminismo e mito, con Benjamin sulla traduzione. Ha dell'incredibile il fatto che non conoscesse invece nemmeno Jung e che, così isolato, se lo sia potuto "logicamente", perfettamente immaginare - come mostra il romanzo Oppiano Licario (inedito in Italia, dove si conosce solo Paradiso). Il suo titanico lascito di saggi in ogni direzione rimane per gli europei inesplorato, forse inesplorabile focus di una bio-logica trans-poesia "glocale"

23. I 40 numeri di "Orígenes" furono "essenzialmente una spirale incessante di conversazione e d'amicizia", racconterà poi Lezama: fiero d'esser riuscito a pubblicarvi la prima traduzione dei Quartetti di Eliot, un inedito di Santayana o di Camus, ecc: "ogni numero conteneva almeno un testo memorabile, che resisteva a questo tempo di rovina e disintegrazione". Una "bottega rinascimentale", cui partecipano creativamente non solo i musicisti (José Ardévol, Julian Orbon) ma persino i tipografi, riproducendo le opere dei massimi pittori cubani (Mariano, Lozano, Portocarrero, Lam, Pelaez), di cui Lezama con sapienza goethiana andava illustrando i rapporti (soprattutto fra i colori puri) con Picasso, Matisse, Murillo, Cezanne, Rousseau il Doganiere.

24. Ma non Carlo Emilio Gadda, al cui parallelo con la sua scrittura, avanzato da qualcuno, si ribella dichiarando meccanico e banale il pastiche gaddiano, mentre il suo avrebbe contenuti essenziali. 


\section{Beats}

\subsection{Allen Ginsberg}

Un secolo dopo Whitman, la Beat Generation prefigura la stagione dei Figli dei Fiori, utopia eroticomunitaria e trans-linguistica, erranza e anti-epos narrativo dell'America quale archetipo della globalizzazione, viaggio "mistico" verso la redenzione sincretista di ogni Cultura nel "selvatico" della natura. La semplicità zen-naturale introdotta dal giapponese Suzuchi ben attecchisce sul trascendentalismo nordamericano da Thoreau a Emerson, al buddhista Huxley al taoista Alan Watts.

Il poeta ebreo-buddhista Ginsberg apre la sua scrittura e voce, il suo corpo all'Altro, al Sud nei tre continenti (Messico, Marocco, India), e più dell'amico, "blues-folk fondamentalista" Dylan, attinge in vita onori da Maestro dell'Occidente ${ }^{25}$. Proprio per il suo sincretismo globale, per la sua wholeness, interezza d'arte-vita, scrittura-corpo, sanità di un uomo disarmato $\mathrm{e}$ disarmante, che con il candore della voce unisce il Sacro e il profano, l'Oriente e l'Occidente, l'illuminazione e la liberazione sessuale. Poeta del quotidiano - più che metro-, cosmopolitano, resistenza della parola come ecologia della diversità e denuncia civile - negli ultimi trent'anni al servizio di un luogo proclamato come sacro ${ }^{26}$, Lower East Side, il quartiere più latino di New York. Un inglese trans-etnopoetico e la voce respirante uniscono e guariscono i presenti. Non troppo diversamente dalla phoné di Carmelo Bene, la poesia “dev'essere canto dell'intero corpo, asserzione di una comune condivisione d'anima tra i membri del corpo politico, unisono e unità con tutta la natura"

Sul ritmo dell'improvvisazione frastica, lunga o breve secondo il respiro del momento, convergono i modi della poesia occidentale cui ha prestato ascolto: la salmodia ebraica Yiddish (il poema Kaddish per la madre paranoica), gli spirituals afroamericani, le "visioni" di William Blake (che gli "detta in sogno" Sunflower), il "parlato" di W. Carlos Williams, il "melting pot" linguistico ma "non-usuraio" di Ezra Pound, l'ode panteista di Walt Whitman e, lontane antenate, le avanguardie europee (incluso lo Sprechgesang di Schönberg), dalle Illuminazioni di Rimbaud al Dadaismo e Majakovskij. Ma, iniziato in India a ogni tipo di mantra, la misura del suo verso discenderà sempre più dalla meditazione buddhista sul respiro qui-ora ${ }^{27}, \mathrm{e}$ l'intonazione dominante della sua recitazione fonderà la tradizione oratoria americana con l'orientale "proclamazione della sacralità di tutte le cose" - esorcismo di quelle negative ed esultanza nella nominazione-illuminazione "profetica" del mondo.

25. Al Centro "Shambhala" di Manhattan, monaci e amici (come Philip Glass e Amiri Baraka) ma anche molti ignoti amanti (invocati nella poesia Death \& Fame scritta un mese prima di morire) per la sua veglia funebre recitarono il Sutra del Cuore della Prajna Paramita, nella puja guidata da Gelek Rimpoche.

26. Su questo aspetto in particolare, si rimanda alla lunga intervista concessa da Ginsberg a chi scrive, pubblicata da "Paramita" 32 , Roma 1989 e "Viceversa" 27, Montreal 1989.

27. Zen Rinzai, Vipassana Theravada, tantrico tibetano Vajrayãna. Con il Nirmanakãya, il "corpo di trasformazione" della sua voce, rimane in contatto con il caos dell'esistenza fenomenica per aiutare gli altri a uscire dal dolore. Ritmando il fiato per nominare gli oggetti immediati della coscienza - "confessione” che già libera l'uditorio - arresta il vortice della mente, che in tale calma si proietta nel Sambhogakãya, nel 
..from: Wichita Vortex Sutra ${ }^{28}$

|1966]

I'm an old man now, and a lonesome man

in Kansas

But not afraid

to speak my lonesomeness in a car

Because not only my lonesomeness

it's Ours, all over America,

O tender fellows -

\& spoken lonesomeness is Prophecy

in the moon 100 years ago or in

the middle Kansas now.

It's not the vast plains mute our mouths

that fill at midnite with ecstatic language

when our trembling bodies hold each other

breast to breast on a mattress -

Not the empty sky that hides

the feeling from our faces

nor our skirt and trousers that conceal

the bodylove emanating in a glow of beloved skin,

white smooth abdomen down to the hair between our legs,

It's not a God that bore us that forbid

our Being, like a sunny rose

all red with naked joy

between our eyes \& bellies, yes

All we do is for this frightened thing

we call Love, want and lack -

fear that we aren't the one whose body could be

beloved of all the brides of Kansas City,

kissed all over by every boy of Wichita -

Obut how many in their solitude weep aloud

like me-

On the bridge over Repubblican River

almost in tears to know da: Wichita Vortex Sutra

(trad. Fernanda Pivano, riveduta da chi scrive)

Ora sono vecchio, e solo nel Kansas

ma non ho paura

di parlare della mia solitudine in macchina,

perché non solo la mia solitudine

è la Nostra, in tutta l'America,

O teneri compagni -

e la solitudine pronunciata è Profezia

100 anni fa sulla luna $o$ in

mezzo al Kansas ora.

Non sono le vaste pianure ad ammutolirci la bocca

che a mezzanotte si riempie di linguaggio estatico

quando i nostri corpi tremanti si stringono

seno a seno sul materasso -

Non è il cielo vuoto a nascondere

le emozioni dai nostri volti

né le nostre gonne e calzoni occultano

il corpo d'amore che emana nello splendore

di una pelle amata,

bianco liscio addome giù fino ai peli fra le nostre

gambe,

Non è un Dio generanteci a vietare

il nostro Essere, come una rosa al sole

tutta rossa di nuda gioia

fra i nostri occhi e il ventre, si

Tutto facciamo per questa cosa impaurita

che chiamiamo Amore, desiderio e mancanza -

paura di non essere quello che il corpo potrebbe se amato da tutte le spose di Kansas City, baciato dappertutto da ogni ragazzo di Wichita O quanti nella loro solitudine piangono forte come me -

Al ponte sul fiume Republican

Quasi in lacrime per trovare

"corpo di beatitudine" - il mondo come visto dai Bodhisattva - e da qui il vortice ritorna come canto purificato, come "corpo giusto" (Dharmakäya) nel rito-sacrificio della poesia vocale.

28. In Allen Ginsberg, Mantra del Re di Maggio, a cura di Fernanda Pivano, Oscar Mondadori, 1973. I versi qui riportati sono letti da Ginsberg con musica di Philip Glass nel Cd Hydrogen Jukebox, Elektra-Warner, Germania 1993. 
how to speak the right language -on the frosty broad road

uphill between highway embarkments

I search for the language

that is also yours -

almost all our language has been taxed by war.

\section{(...)}

A lone man talking to myself, no house in the brown vastness to hear, imagining the throng of Selves

that make this nation one body of Prophecy languaged by Declaration as Happiness!

I call all Powers of Imagination

to my side in this auto to make Prophecy,

all Lords

of human kingdoms to come

Shambu Bharti Baba naked covered with ash

Khati Baba fat-bellied mad with the dogs

Dehorahava Baba who moans Oh how wounded,

How wounded

Citaram Onkar DasThakur who commands

give up your desire

Satyananda who raises two thumbs in tranquillity

Kali Pada Guha Roy whose yoga drops before the void

Shivananda who touches the breasts and says $O M$

Srimata Krisnaji of Brindaban who says take

for yourguru

William Blake the invisible father of English visions

Sri Ramakrisna master of ecstasy eyes

half closed who only cries for his mother

Chaitanya arms upraised singing \& dancing his own praise il linguaggio giusto -

sullo stradone gelato

in mezzo alle scarpate dell'autostrada

cerco il linguaggio

che sia anche vostro -

quasi tutto il linguaggio è tassato dalla guerra.

\section{(...)}

Solitario parlante a me stesso, nella buia vastità non c'è una casa che mi senta,

immagino la folla di Io

che fa questa nazione un sol corpo di Profezia pronunciata come Dichiarazione di Felicità!

Invoco al mio fianco, in quest'auto, tutti i Poteri dell'immaginazione per fare la Profezia, tutti i Signori

dei regni umani a venire

Shambu Bharti Baba nudo coperto di cenere Khati Baba panciuto infuriato coi cani

Dehorahava Baba che geme Oh che ferita, Che ferita

Citaram Onkar DasThakur che ordina di rinunciare ai desideri

Satyananda che alza i pollici in serenità

Kali Pada Guha Roy il cui yoga stilla di fronte al vuoto

Shivananda che si tocca i seni dicendo OM Srimata Krisnaji di Brindaban che dice prendi per guru

William Blake, padre invisibile delle visioni inglesi

Sri Ramakrisna maestro d'estasi a occhi socchiusi che piange solo per sua madre Chaitanya con le braccia in alto che canta e danza le sue lodi 
merciful Chango judging our bodies

Durga-Ma covered with blood destroyer of battlefield illusions

millions faces Thatagata gone past suffering Preserver Harekrisna returning in the age of pain

Sacred Heart my Christ acceptable

Allah the Compassionate One

Jaweh Righteous One

All Knowledge-Princes of Earth-Man, all

Ancient Seraphim of heavenly Desire, Devas, yogis \& holymen I chant to-

Come to my lone presence

into this Vortex named Kansas,

Ilift my voice aloud,

make Mantra of American language now,

I here declare the end of the War!

Ancient days'Illusion! -

and pronounce the words beginning my own millennium.

Let the States tremble,

let the Nation weep,

let the Congress legislate its own delight

let the President execute his own desire -

this Act done by own voice,

nameless Mystery -

published to my own senses,

blissfully received by my own form

approved with pleasure by my sensations

manifestation of my very thought

accomplished in my own imagination

all realms within my consciousness fulfilled
Chango misericordioso che ci giudica il corpo

Durga-Ma coperta di sangue

distruttrice delle illusioni di lotta

i mille volti del Thatagata giunto oltre il dolore

Harekrisna il Custode che vi ritorna

il Sacro Cuore del mio Cristo accettabile

Allah il Compassionevole

Jaweh il Giusto

Tutti i Prìncipi di conoscenza dell'uomo-Terra, tutti gli antichi Serafini del desiderio celeste, i

Deva, gli yogi

E i sant'uomini io canto -

Venite alla mia sola presenza

in questo vortice chiamato Kansas,

levo alta la mia voce, ora

per fare il Mantra della lingua americana,

e dichiaro la fine della Guerra!

l'Illusione dell'Ancient Days! -

e pronuncio le parole d'inizio del mio millennio,

Che tremino gli Stati,

che la Nazione pianga,

che il Congresso legiferi il suo piacere

che il Presidente mandi a morte il suo desiderio-

questa è Legge fatta dalla mia voce,

Mistero senza nome -

pubblicato per i miei sensi,

beatamente ricevuto dalla mia forma

approvato con piacere nelle mie sensazioni

manifestazione del mio vero pensiero

compiuto nell'immaginazione

esaudito ogni reame della mia coscienza

Sciogliere l'allegoria del potere politico, militar-nucleare, scientifico-distruttivo, consumistainquinante - come le nevrosi, ossessioni e debolezze private - è così per Ginsberg una "via di mezzo", fra il trascenderli in un sessual-tantrico nirvana e l'attraversarli esasperandoli (come 
il Living Theatre). Il verso, povero o allucinato, vive in uno straniamento meditativo e ludico, che cordialmente unisce le due scale simboliche, la voce costruttiva (soggettiva) della poesia e quella de-costruttiva (storicamente necessaria) della meditazione, di-mostrandone la specularità ("la forma è vuoto, il vuoto è la forma").

Certo, la decostruzione che dà piena cittadinanza a qualsiasi banalità quotidiana corre il rischio continuo del kitsch, eco amplificata dell'insignificanza, il linguaggio del mondo che voleva esorcizzare. Così, se incalcolabile ma già sommersa al volgere del millennio è stata l'influenza del messaggio transculturale beat ("espansione della coscienza") di Ginsberg, più duratura è quella della sua oralità che, oltre ai sincretismi hi-tech o le soffici spire New Age, è riferimento obbligato per ogni riscoperta e sperimentazione vocale fra musica e poesia, fra denunce e proclamazioni di (o per) moltidudini desideranti - dagli Slam Poetry di Mark Smith alle performance di Rosaria Lo Russo e Lello Voce in I talia.

\subsection{Jack Kerouac}

Quando nel '74 Ginsberg fu chiamato da Chogyam Trumpa a fondare il Naropa Institute a Boulder Colorado (divenuto prestigiosa Università transculturale), intitolò la scuola di "poetica incorporea" (Disembodied Poetics) a Jack Kerouac, il suo primo maestro di buddhismo Zen e di scrittura in "spontanea prosodia bop" - novità rispetto al surrealismo europeo o al "flusso di coscienza" di Joyce. La scrittura di Kerouac mira a trasfondere l'haiku zen nella frase del sassofono di Charlie Parker (e viceversa la sua lettura ad alta voce) - una doppia versione di linguaggi da lui considerati alti e universali. Nella sua poetica ${ }^{29}$, dice di fare letteralmente la parodia del tema musicale che sente al momento, o dell'"immagine - gioiello centrale" su cui in semitrance "soffia, soffia profondo", dall'interno verso fuori come il sassofonista jazz. Come questi fa le pause per riprendere fiato, cosi l'unico segno grafico nella prosa dovrebbe essere "il vigoroso trattino a separare il respiro retorico". Alan Watts includeva nello Zen Beat ${ }^{30}$ ("sregolatezza protestante con troppa autocoscienza") anche la pietas un po" "cattolica" di Kerouac - americano quasi québecois, di origine bretone con apporti Mohawk e Caughnawaga. Un'intensa, francescana ingenuità, il senso leggero e insieme tragico dell'imperfezione che accomuna e tutti assolve già in un Paradiso-ora, s'inverano nel suo zen esistenziale e in interi volumi di scritture buddhiste. Dire tutto e il contrario di tutto è del resto uno dei modi tipici della logica Madiamikä, e La Scrittura della Dorata Eternità lo usa insieme ad altri paradigmi mistici, creando nella letteratura occidentale un raro "gioiello" sincretico, il manifesto di un'estasi "orientalista" certo troppo "facile", ma imprescrittibile e ineguagliato segno dei tempi.

29. Essentials of Spontaneous Prose, in "Black Mountain Review" 1957, e Belief \& Technique for Modern Prose, in "Evergreen Review" 1959. Entrambi ora tradotti in Battuti e Beati, a cura di E. Bevilacqua, Torino 1996.

30. "Lo Zen Beat con lo zen vuol giustificare il capriccio nell'arte (le opere) e nella vita, godendosi l'universo come Snyder, Ginsberg, Kerouac", in Alan Watts, Zen Beat, "Chicago Review" estate '58, scritto dopo The Way of Zen (I957), poi ampliato e con altri saggi uscito per la CityLights di Lawrence Ferlinghetti (S. Francisco, 1960) col titolo This is It (trad. italiana Questo è il "tutto"Arcana, Roma '73). 
from: The scripture of Golden Eternity [1956]

14.

What name shall we give it which hath no name, the common eternal matter of the mind? If we were to call it essence, some might think it meant perfume, or gold, or honey. It is not even mind. It is not even discussible, groupable into words; it is not even endless, in fact it is not even mysterious or inscrutably inexplicable; it is what is; it is that; it is this. We could easily call the golden eternity "This." But "what's in a name?" asked Shakespeare. The golden eternity by another name would be as sweet. A Tathagata, a God, a Buddha by another name, an Allah, a Sri Krishna, a Coyote, a Brahma, a Mazda, a Messiah, an Amida, an Aremedeia, a Maitreya, a Palalakonuh, 12345678 would be as sweet. The golden eternity is $\mathrm{X}$, the golden eternity is $\mathrm{A}$, the golden eternity is $\wedge$, the golden eternity is $\mathrm{O}$, the golden eternity is [], the golden eternity is t-h-e-g-o-l-d-e-n-e-t-e-r- n-i-t-y. In the beginningwas the word; before the beginning, in the beginningless infinite neverendingness, was the essence. Both the word "god" and the essence of the word, are emptiness. The form of emptiness which is emptiness having taken the form of form, is what you see and hear and feel right now, and what you taste and smell and think as you read this. Wait awhile, close your eyes, let your breathing stop three seconds or so, listen to the inside silence in the womb of the world, let your hands and nerve-ends drop, re-recognize the bliss you forgot, the emptiness and essence and ecstasy of ever having been

\author{
da: La scrittura della Dorata Eternità \\ (traduzione di Silvia Piraccini ${ }^{31}$ \\ riveduta da chi scrive)
}

14.

Che nome dovremmo dare a ciò che non ha nome, all'eterna materia comune della mente? Se dovessimochiamarlaessenza, qualcunopotrebbe credere che significhiprofumo, o oro, omiele. Non è nemmeno mente. Non è nemmeno discutibile, raggruppabile in parole; non è nemmeno senza fine, in effetti non è nemmeno misteriosa o inscrutabilmente inesplicabile; è ciò che è; è quello; è questo. Potremmo chiamare la dorata eternità semplicemente "questo". Ma "che cos"è in un nome?" chiedeva Shakespeare. La dorata eternità conaltro nomeandrebbe altrettantobene. Un Tathagata, un Dio, un Buddha con altro nome, un Allah, un Sri Krisna, un Coyote, un Bhrama, un Mazda, un Messiah, un Amida, un Aremedeia, un Maitreya, un Palalakonouh, 1, 2, 3, 4, 5, 6, 7,8 andrebbe altrettanto bene. La dorata eternità è $X$, la dorata eternità è $A$, la dorata eternitàè $\wedge$, la dorata eternitàè $O$,ladorataeternitàè [],ladorata eternità è la d-o-r-a-t-a-e-t-e-r-n-i-t-à. All'inizio fu laparola; prima dell'inizio, nell'infinito senza inizio e senza fine, era l'essenza. Ed entrambe le parole, "dio" el'essenza della parola sono vuoto. La forma del vuoto che è vuoto avendo preso la forma della forma, è quello che vedi e odi e senti esattamente adesso, e quello che assapori e odori epensi mentre leggi questo. Aspettaun momento, chiudi gli occhi, ferma per qualche secondo il respiro, ascolta il silenzio interiore nel grembodel mondo, rilassale mani e le terminazioni nervose, ri-riconosci la beatitudine che hai dimenticato, il vuoto e l'essenza e l'estasi di essere sempre 
and ever to be the golden eternity. This is the lesson you forgot.

\section{6}

Give a gift to your brother, but there's no gift to compare with the giving of assurance that he is the golden eternity. The true understanding of this would bring tears to your eyes. The other shore is right here, forgive and forget, protect and reassure. Your tormenters will be purified. Raise thy diamond hand. Have faith and wait. The course of your days is a river rumbling over your rocky back. You're sitting at the bottom of the world with a head of iron. Religion is thy sad heart. You're the golden eternity and it must be done by you. And means one thing: NothingEver-Happened. This is the golden eternity.

\section{4}

I was smelling flowers in the yard, and when I stood up I took a deep breath and the blood all rushed to mybrain and I woke up dead on myback in the grass. I had apparently fainted, or died, for about sixty seconds. Myneighbor saw me but he thought I had just suddenly thrown myself on the grass to enjoy the sun. During that timeless moment of unconsciousness I saw the golden eternity. I saw heaven. In it nothing had ever happened, the events of a million years ago were just as phantom and ungraspable as the events of now, or the events of the next ten minutes. It was perfect, the golden solitude, the golden emptiness, Something-Or-Other,somethingsurely humble. There was a rapturous ring of silence abidingperfectly. There was no question of being alive or not being alive, of likes and dislikes, of near or far, no question of giving or gratitude, no stato ed essere per sempre la Dorata Eternità. Questa è la lezione che hai dimenticato.

36.

Fai un dono a tuo fratello, ma non c'è dono comparabile all'assicurargli che lui è la dorata eternità. La vera comprensione di questo ti farà brillare gli occhi di lacrime. L'altra riva è già qui, perdona e dimentica, proteggi e rassicura. Chi ti tormenta verrà purificato. Alza la tua mano di diamante. Abbi fede e aspetta. Il corso dei tuoi giorni è un fiume che risuona sul tuo dorso roccioso. Stai sedendo al fondo del mondo con un capo di ferro. La religione è il tuo triste cuore. Tu sei la dorata eternità e dev'essere fatta da te. E significa una cosa: Nulla-Mai-E-Accaduto. Questa è la dorata eternità.

64.

Sentivo il profumo dei fiori nel giardino, mi levavoperun respiroprofondoeil sangue m'irrorò tutto il cervello, mi svegliai con la schienasull'erba. Evidentemente ero svenuto, o morto, per circa sessanta secondi. Il vicino mi vide ma pensò che mi fossi d'un tratto buttato nell'erbapergodermi il sole. In quell'attimo senza tempo d'incoscienza vidi la dorata eternità. Vidi il cielo. Dove niente era mai accaduto, gli eventi d'un milione di anni fa erano fantasmi inafferrabili proprio come gli eventi di adesso, o quelli dei prossimi dieci minuti. Eraperfetta,ladorata solitudine, ladorata vacuità, Qualcosa-o-l'altra, qualcosa certodiumile. C'eraun estatico anellodi silenzio perfettamente raccolto. Non era in questione l'esser vivio il non esserlo, piacere o non piacere, vicino o lontano, nemmeno il dare o la gratitudine, la pietà o il giudizio, il soffrire o qualsiasi altra cosa. Era il 
question of mercy or judgment, or of suffering or its opposite or anything. It was the womb itself, aloneness, alaya vijnana the universal store, the Great Free Treasure, the Great Victory, infinite completion, the joyful mysterious essence of Arrangement. It seemed like one smiling smile, one adorableadoration, onegracious and adorable charity, everlasting safety, refreshing afternoon, roses, infinite brilliant immaterial gold ash, the Golden Age. The "golden" came from the sun in my eyelids, and the "eternity" from my sudden instant realization as I woke up that I had just been where it all came from and where it was all returning, the everlasting So, and so never coming or going; therefore I call it the golden eternity but you can call it anything you want. As I regained consciousness I felt so sorry I had a body and a mind suddenly realizing I didn't even have a body and a mind and nothing had ever happened and everything is al right forever and forever and forever, O thank you thank you thank you. grembo stesso, la solitudine, alaya vijnana il deposito universale, il Grande Tesoro Libero, la Grande Vittoria, la completezza eterna, la gioiosa misteriosa essenza della Disposizione. Pareva un unico sorriso sorridente, un'unica adorabile adorazione, una graziosa e adorabile carità, sicurezza infinita, pomeriggio ristoratore, rose, infinita immateriale brillantepolvere dorata, l'Età dell'Oro. L'oro arrivava dal sole dentro le mie palpebre, e l'eternità dal mio istantaneo capire, al risveglio, di essere appena stato là da dove tutto proveniva e dove tutto ritornava, l'eterno Così, e che cosi né andava né veniva; perciò la chiamo Dorata Eternità, ma tu puoi chiamarla come vuoi.Quando ripresiconoscenza, mi dispiacque tanto di avere un corpo e una mente, a un tratto capendo che non li avevo nemmeno, un corpo e una mente, e che nulla era mai successo e tutto è a posto per sempre nei secoli dei secoli, Oh grazie grazie grazie.

\subsection{Gary Snyder}

Com’è noto, il traduttore di antiche poesie cinesi Japhy Rider, mèntore e compagno di scalate nell'autobiografico I Vagabondi del Dharma di Jack Kerouac, non è che Gary Snyder - al cui invito a scrivere un "sutra" l'amico rispose con La Dorata Eternità. La poesia di Snyder è il ceppo di un "beat" fin dall'inizio radicalmente non-metropolitano, pioniere di un "sincretismo buddhistataoista-pagano-animista, una civiltà pan(post) umana e trans-erotica”. Singolarissimo carattere non solo di poeta (Educated Native American, ha insegnato infine all'Ucla-Davis University, "felice di essere un parlante Inglese, lingua cosi flessibile e creativa"), ma anche taglialegna, fondatore di comunità con Nanao Sakaki, scalatore del Pacifico settentrionale dall'Alaska al Giappone - dove a Kyoto segui un decennio di iniziazioni Rinzai. A "ri-abitanti della terra" e poeti della natura 
(persino in un'Italia cosi distante per basi culturali) il suo corpus di studi e incontri etnopoetici ha trasmesso un metodo, nella "lingua franca" della poesia come ri-sanante Narrazione della Natura. I suoi saggi di "ecologia profonda"32 sono una sorta di antropologia transculturale del selvatico - fiera "sapienza" vitale degli ecosistemi naturali e sacra, misteriosa origine dei miti umani nelle lingue vernacolari, cui il poeta vichianamente partecipa e attinge con l'immaginazione - quale porta-voce ${ }^{33}$, antenna sciamanica, traduttore simultaneo-liberando o evolvendo spiriti incatenati, come nell'auto-poietica Illuminazione buddhista.

Snyder cerca invarianti o inventa traduzioni etnopoetiche di miti lontani ${ }^{34}$. Identificandosi più con quelli del Pacifico settentrionale che con quelli europei, ama impersonare The Hump-backed Flute-Player, il Gobbo Suonatore di Flauto, cioè il vecchio uomo-coyote "il cui sterco contiene le tracce di tutti i cicli animali: perché il gabbamondo di tante storie (svelto, furbo, lascivo, e con un buon bagaglio di conoscenza; un ribelle, un sopravvissuto) rompe loccidentale dicotomia Bene-Male e ricorda che saggezza e stupidità si mischiano come il ghee nel latte (un'antica metafora buddhista per il non-dualismo)" "Con un po' d'audacia" paragonandosi a Zeami, che immettendo in arcaiche tradizioni giapponesi l'intuizione buddhista Mahayana le trasformò nelle pièce di arte colta del teatro Noh - Snyder porta nell'emisfero occidentale ${ }^{35}$ fra le altre la figura della strega demonessa Yamamba, l'Orca o Vecchia della Montagna, in una forma che in parte echeggia la tradizione nativo-americana degli spiriti selvaggi e le scoperte dei geologi. Forse Turtle Island ha valso a Snyder il Premio Pulitzer 1975 per aver ardito ribattezzare il NordAmerica Isola della Tartaruga: auspicio di stabilità e longevità delle terre emerse e protette dal cielo in ogni Tradizione, simbolo della materia prima per l'opera alchemica ${ }^{36}$.

Se tutto ciò è chiaro e ben sviluppato nei saggi, la sua scrittura poetica ne è una contrazione, la rarefatta stenografia del diario di viaggiatore, l'istantaneo haiku che illumina la stratigrafia del poema della natura, la millenaria danza di trasformazione di tutti gli esseri, lungo le catene analogiche fra montagne e fiumi. L'esecuzione vocale è perfettamente conforme: spesso ridotta a monosillabi, come colpi di pennello, ideogrammi librati in aria, soffi leggeri e decontaminanti, che ri-sanano svuotando, asciugando o cauterizzando in un secco narrativo, o aprendosi in un mantra: danza della parola che rivela uno stile del vuoto.

32. O ecosofia, del norvegese Arne Naess, che affonda le sue radici nell'etica panteista di Spinoza, nella psicologia della Gestalt e nella lotta "non-violenta" di Gandhi.

33. Dal ' 69 in Sierra Nevada la sua dimora è immersa nella foresta che risuona dei versi di piante animali, degli umori e tracce del loro spirito: Kitkitdizze, dal nome che la gente Wintun dava a un'erba aromatica del sottobosco locale.

34. Trova figure indimenticabili come il "The Big Brown One", l'Orso-Orsa polare (il regale Fudo Myoô, l'antenato per gli Yamabushi, yogi shinto-buddhisti della montagna; il Kamui Kimun degli Ainu, dipinto nelle grotte e affine a un Bodhisattva; le sciamane-orso finnico-siberiane: forse attraverso Bjorn-Braun-Bear deriverebbe il nome Brunhilde; certo la svizzera Berna, sede di una dea Artio, nome che risuona nei cicli di Re Artù, poi in Arturo; citando i Pitagorici - "le Orse sono le mani di Rea" - vede "scivolare sull'arcobaleno/la Gioia delle Montagne / Lei Grande Orsa”). Madre Terra e le sue Balene ci ricorda che ancora nel 1619 Keplero paragonava la Terra a un'enorme balena, i cui respiri danno luogo alle maree.

35. Alla Maison de la Culture du Japon di Parigi, dicembre 2002, ha commentato il sutra di Hakuin sulla "vera (nessuna) natura della natura", e quindi letto dal suo Mountains and Rivers without End, accompagnato da musicisti del teatro Noh. Su "Dharma" (13, 2004) è pubblicata l'intervista concessa a chi scrive in quell'occasione.

36. Sul mensile "Poesia" (126, marzo 1999) chi scrive presentò con traduzione a fronte una ventina di poesie e la sua opera in chiave alchemica. 
from: Regarding Wave

Wave

Grooving clam shell, streakt through marble, sweeping down ponderosa pine bark-scale rip-cut tree grain sand-dunes, lava flow

Wave wife. woman-wyfman-

"veiled; vibrating; vague" sawtooth ranges pulsing; veins on the back of the hand.

Forkt out: birdfoot-alluvium wash

great dunes rolling

Each inch rippld, every grain a wave.

Leaning against sand cornices till theyblow away

- wind, shake

stiff thorns of cholla, ocotillo

sometimes I get stuck in thickets -

Ah, trembling spreading radiating wyf racing zebra

catch me and fling me wide

To the dancing grain of things of my mind!

\section{da: Rivedendo L'onda}

Onda

La scanalata conchiglia di un mollusco, striata nel marmo, le linee della scorza del Pino Ponderoso lacerata grana dell'albero dune di sabbia, fluire di lava

Onda sposa.

$$
\text { Donna-domina - }
$$

"velata; vibrante; vaga" le dentate montagne pulsanti; le vene sul dorso della mano.

Le inforcature: il bacino alluvionale a zampa d'uccello

il rotolio delle grandi dune Ogni centimetro increspato, ognigranello un'onda.

Poggiano su cornici di sabbia finché volano via

$$
\begin{aligned}
& \text { - il vento, scuote } \\
& \text { secche spine di Opuntia, Fouquieria } \\
& \text { a volte rimango preso fra gli arbusti - }
\end{aligned}
$$

Ah, la tremante dilagante raggiante donna la gareggiante zebra

mi prende e m'impenna sulla grana delle cose danzante nella mia mente! 
from: No Nature

How Poetry Comes to Me

It comes blundering over the

Boulders at night, it stays

Frightened outside the

Range of my campfire

I go to meet it at the

Edge of the light

From: Myths \& Texts

\section{Lodgepole}

cone / seed waits for fire

And then thin forests of silver-gray.

in the void

apine cone falls

Pursued by squirrels

What mad pursuit! What struggle to escape!

Her body a seedpod

Open to the wind

"A seed pod void of seed

We had no meeting together"

so you and I must wait

Until the next blaze

Of the world, the universe,

Millions of worlds, burning

- oh let it lie.

\section{da: Non Natura}

Come mi giunge la poesia

Viene alla cieca sui massi la notte, rimane impaurita fuori dal raggio del mio falò Vado a incontrarla sul bordo della luce.

da: Miti e Testi

Il seme / cono

del Lodgepole attende il fuoco

$\mathrm{E}$ poi le fini foreste grigio argento. nel vuoto cade una pigna

Inseguita da scoiattoli

Che inseguimento folle! Che lotta per scampare!

Il suo corpo un baccello da semi

aperto al vento

"un baccello vuoto di seme

non abbiamo avuto un incontro" così tu ed io dobbiamo attendere

fino alla prossima vampa

del mondo, l'universo,

milioni di mondi, in fiamme

- oh bugie. 
Shiva at the end of the kalpa:

Rock - fat, hill - flesh, gone in a whiff.

Men who hire men to cut groves

Kill snakes, build cities, pave fields,

Believe in god, but can't

Believe their own senses

Let alone Gautama. Let them lie.

Pine sleeps, cedar splits straight

Flowers crack the pavement.

Bada Shanren

(A painter who watched Ming fall)

lived in a tree:

"The brush

May paint the mountains and streams

Though the territory is lost"
Shiva alla fine del kalpa:

grasso di roccia, collina di carne, via in un soffio.

Uomini che assumono uomini per tagliare boschi

uccidere serpenti, costruire città, cementare campi,

credono in dio, ma non possono

credere ai loro sensi

a parte Gotama. Lasciamoli mentire.

Dorme il pino, s'innalza dritto il cedro.

Fiori spaccano l'asfalto.

BadaShanren

(un pittore che vide la caduta dei Ming)

visse dentro un albero:

"Il pennello

può dipingere montagne e fiumi

anche se il territorio è perduto"

"Ogni arte e canto / sono sacri al reale / come tale" sussurra "lo spirito della montagna", ma "l'intero universo fenomenico non è che un dipinto di luce abbagliante. Un dipinto è l'illuminazione massima" aggiunge Dôgen (come Leonardo). Nel selvatico di Snyder, teoria del linguaggio e teoria della natura coincidono: "ogni cosa, vista a occhi nudi e chiusi, dolce" vien detta in poesia, perché solo il "reale" illuminato da compassione diviene tale - significante libero da giudizi, significato connesso agli infiniti altri.

\section{Carmelo Bene}

Nessuno più di Bene appare autoconfitto nell'Inferno dantesco, la cantica davvero amata dagli italiani, sulla cui lingua concludiamo questo breve excursus. Se l'italianissima voce di Carmelo Bene è d'altra parte cosi estranea, così straniera proprio agli italiani, si deve a quel "depensamento poetante" deleuziano che è la cifra di Bene anche ne 'lmal de'fioripoema (Milano 2000). Testamento, scritto e non letto in vita (indecidibile ormai la sua vocalità), verbale però di un'oralità epiconirica e trans-linguistica - dove prevalgono i vernacoli italici (tosco, pavano, napoletano, romanesco, siculo, salentino), o il provenzale e l'ispanico - declinati in pasticcio arcaico-attuale. 


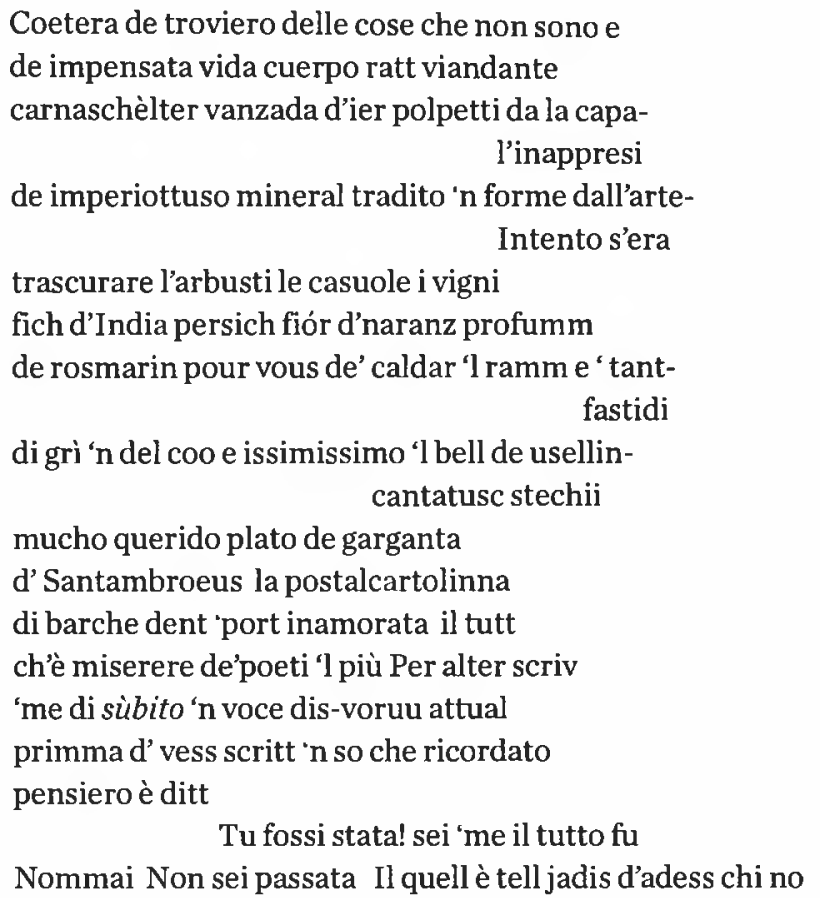

Sergio Fava enumera le figure diquesto corpus barocco (controcanto anche alla scultura, dal Bernini a "Michelaccio l'Angelo", al neoclassico "MinchioneWinckelmann") - figure che sono poi quelle prosodiche di Bene "straniero alla sua lingua" (e al pubblico): sprezzatura stilnovista, ariostesca (o meglio, cervantina), maccheronica fierezza, acido corrosivo di Laforgue, eroismo rabelaisiano del ridicolo, virulenza comica, costante hölderliniana e campaniana. Sono le tonalità emotive, tipiche e popolari, qui disanimate e straniate in una gnostica "nostalgia delle cose che non furono mai" nella "nolontà di non essere mai stati" - bordone andante un poco maestoso del poema. "Non mi ero mai imbattuto nella nostalgia delle cose che non furono mai" dice nell'autointervista, ma il "da sempre mancato, il nomadismo" contamina tutto il poema come la "similvita": dalla donna e l'amore ("cosa eri, tra cose" "questo ch"è tuo non essere mai stata" "Noi non ci apparteniamo. È il mal de' fiori / Tutto sfiorisce in questo andar ch'è star / inavvenir / Tutto è passato senza incominciare"), all'eros stesso - la cui imperdonabile colpa è di essere anche Logos, pulsione 
coito-logica della copula, ciò che - dicendo è - produce l'orrore della maternità e "resurrezione" (nel senso di moltiplicazione della specie).

Una sintassi ossimorica màcina il flusso della natura in-animata dal dolore: "Vanito 'n apparir Somiglia "l sole / in sorger tramontato", "Di non morir si dole forse di / non essere quel fiore non mai stato". Dove mai può esistere con-jugazione, e dove gli enjambement spezzano il ritmo della frase, la logica della voce - alla quale anziché darlo, tolgono il respiro. Carmelo Bene senza respiro? Certo, come voce il cui fiato mai aderisce all'ordine emotivo, al senso "poetico" - ma asincrona e fuori campo va azzerando le differenze fra pensiero organico e minerale - parola pura nel suo stroppiarsi in "ricetta farmaceutica di controindicazioni" o in musicale impromptu - collane di perle, accordi e dissonanze alla Keith Jarrett. Bene "italianizza" così lo s-parlarsi addosso fisiologico, chimico, ideologico della totalità dei corpi, svuotando l'inconscio rivendicare un'anima inesistente ("Come se si potesse essere autori di qualcosa!"), in una "naturale" sfigurazione della lingua - cortocircuiti verbal-fonici o imprevisti smottamenti fra un idioletto e l'altro - e giunge a una "alchemica" nigredo o combustione in cui il tantra orientale si assimila alla nostra pornografia, appagamento senza desiderio.

\section{PAVANA a mo' d'addio}

Quanto che fu esentato d'artificio somiglia l'impensato delle cose che non furono mai Pure v'è come patetico un rimpianto Un mal d'amore mancato in si star qui che strano e vago vago e strano duole 'me se perduto quasi 'me morir d'ecco son voci e sordo è il tuo sentire ché m'hai parlata mai 'me rosa e viola dapersempre non sono fiorite sulle tue labbra mute in non le dir

Non m'hai pensata $\grave{E}$ tardi non m'hai chiamata Cosa fra tante non mai state sembrano 'me sfiorite 


\author{
Non come quelle d'arte mai formate \\ da nessuno rimpiante \\ s'espresse a durar fuor d'ogni stagione \\ immortali presunte \\ Fuor dell'arte mancata fra le cose \\ che non sono tu m'hai evocata mai \\ da che silente addio "me se dimentica \\ nata sarei a sfiorir \\ 'me viola e rosa breve tua l'amata \\ d'un attimo mai più.
}

Contro la "ruminazione, digestione, fonazione e flatulenza di ogni arte poetica", è "il Cordelcorp al di là del desiderio", e questa voce "non tua non mia". Quasi le stesse parole di Kerouac ("Nulla è mai avvenuto") più che nihilismo declinano qui un neoartaudiano kamikaze culturale - eppure devono pure accadere versi come: "Niente ha fine se non fu" "nel punto questo / il solo istante della vita" "v'è inciso un al di là del dispiacere di che manca salute" Vive la sanità soltanto dell'insania, un'eternità non dorata, ma in bianco e nero - che nei film è coloratissima apologia dei “cretini che vedono la Madonna e hanno ali improvvise" - l'impossibile nolontà mistica "d'essere il più gentile, il più cretino". Trans-poesia "glocale" più d'ogni altra forse destinata alla scomparsa, dicendo ciò che sempre più è, sarà, è stato - il mai avvenuto svanir dell'illusione. 